Thorax, 1978, 33, 283-289

\title{
Double outlet right ventricle: clinical and anatomical spectrum
}

\author{
E. K. WEIR, ${ }^{1}$ H. S. JOFFE, C. N. BARNARD, AND W. BECK \\ From the Departments of Medicine (Cardiac Clinic), Paediatrics, and Cardiothoracic Surgery, \\ University of Cape Town, South Africa
}

Weir, E. K., Joffe, H. S., Barnard, C. N., and Beck, W. (1978). Thorax, 33, 283-289. Double outlet right ventricle: clinical and anatomical spectrum. Thirty-two patients with double outlet right ventricle (DORV) were studied between 1960 and 1976. Associated congenital defects frequently compounded the difficulty of clinical diagnosis. Cardiac catheterisation was performed in 27 patients, and the ventriculograms were studied with particular regard to the relative positions of the great vessels to each other and to the ventricular septal defect. These relationships determine which corrective operation is possible. Correction has been performed in 12 patients with a perioperative mortality of $25 \%$.

Although mitral-aortic discontinuity was demonstrated in all cases, consideration of the anatomical spectrum included in the term DORV suggests that discontinuity is not an essential feature. In common with other clinical data and in contrast with necropsy studies, none of our patients was found to show the normal relationship of the great vessels to each other, in which the aorta lies posterior and to the right of the pulmonary artery. The reason for this difference between the clinical and necropsy findings is not apparent. A similar disparity was shown with regard to pulmonary stenosis, which was demonstrated at catheterisation in $68 \%$ of the 27 patients (mean gradient $68 \pm 3 \mathrm{mmHg}$ ), in contrast with incidences of $18 \%$ and $25 \%$ in recent necropsy series. Patients in the necropsy studies were frequently neonates or infants, in whom death may have been the result of intractable cardiac failure secondary to excessive pulmonary blood flow. In older patients without pulmonary stenosis and with pulmonary hypertension, frequent observation is imperative so that surgical treatment can be instituted before the development of irreversible pulmonary vascular disease.

The term double outlet right ventricle (DORV) was first used by Witham in 1957, but he pointed out that the condition had been recognised since 1875. The name DORV applies to one abnormality in a spectrum of cardiac anomalies. This spectrum includes the range of conotruncal abnormalities from tetralogy, through the different forms of DORV, to complete transposition (Lev et al., 1972). Within the confines of DORV the relationship of the great vessels can vary from the normal situation, through the side by side position, to one of complete transposition. Transposition in this instance is better termed malposition as both vessels arise from one ventricle (Van Praagh, 1973). The clinical presentation of DORV fre-

${ }^{1}$ Present address: Department of Cardiology, Wentworth Hospital, PB Jacobs, Natal 4026, South Africa quently resembles that of tetralogy of Fallot or ventricular septal defect (VSD), and diagnosis is made more difficult by the frequency of associated cardiac defects. Variations in the relationship of the great vessels to each other and to the VSD demand different procedures in the surgical correction of DORV. This paper analyses the current problems in the diagnosis and management of DORV with particular regard to the relative positions of the great vessels and the VSD.

\section{Patients}

The diagnosis of DORV was established in 32 patients who attended Groote Schuur or Red Cross Children's Hospital between 1960 and 1976. The diagnosis was made at necropsy in eight cases and 
at cardiac catheterisation in 24 patients. Operation or necropsy provided confirmation in 14 of the latter group. In each case both great vessels arose from the morphological right ventricle, so that a VSD provided the only outflow from the left ventricle. Patients with a single ventricle were excluded from the study. The 32 patients with DORV included 19 males and 13 females. Fourteen were under 1 year of age at the time of diagnosis, 13 were between 1 and 10 years, and only five were older than 10 years.

\section{Clinical data}

Twenty-seven patients were examined by a cardiologist during life. The clinical features varied according to the presence or absence of pulmonary stenosis (valvar or infundibular) (Table 1). The clinical presentation of the 18 patients with right ventricular outflow tract obstruction mimicked that of the tetralogy of Fallot, with squatting, cyanosis, clubbing, polycythaemia, and pulmonary oligaemia. The remaining nine patients without right-sided obstruction had signs suggestive of a large VSD. However, in both groups the diagnosis was complicated by the presence of associated defects (Table 2).

Cardiac catheterisation was performed in all 27 patients, and the haemodynamic data obtained reflected the presence or absence of pulmonary stenosis (Table 3 ). When there was no pulmonary stenosis there was usually a large left-to-right

Table 1 Clinical features

\begin{tabular}{lll}
\hline & $\begin{array}{l}\text { With pulmonary } \\
\text { stenosis }(n=18)\end{array}$ & $\begin{array}{l}\text { Without pul- } \\
\text { monary stenosis } \\
(n=9)\end{array}$ \\
\hline Age at diagnosis (years) & $6 \cdot 2$ & $3 \cdot 4$ \\
Squatting & $64 \%$ & $0 \%$ \\
Cyanosis & $83 \%$ & $25 \%$ \\
Clubbing & $81 \%$ & $12 \%$ \\
Haemoglobin (g/dl) & $18.0 \pm 0.9$ & $12 \cdot 6 \% \pm 0.6$ \\
Oligaemia & $60 \%$ & $0 \%$ \\
Electrocardiogram & $47 \%$ & $14 \%$ \\
Left axis deviation & $88 \%$ & $100 \%$ \\
Right ventricular hypertrophy & $6 \%$ & $44 \%$ \\
Left ventricular hypertrophy & $6 \%$ & \\
\hline
\end{tabular}

Table 2 Associated anomalies

Valvar and/or infundibular pulmonary stenosis

Patent ductus arteriosus (PDA)

PDA, hypoplastic aortic arch, and coarctation

Secundum atrial septal defect

Anomalous coronary artery across right ventricular outflow

Pulmonary artery branch stenosis

Dextrocardia with situs inversus

Atrioventricular canal

In some patients there was more than one associated defect.

Only four patients had no other anomaly.
Table 3 Cardiac catheterisation data

\begin{tabular}{lll}
\hline & $\begin{array}{l}\text { With pulmonary } \\
\text { stenosis } \\
(n=18)\end{array}$ & $\begin{array}{l}\text { Without pul- } \\
\text { monary stenosis } \\
(n=9)\end{array}$ \\
\hline $\begin{array}{l}\text { Gradient (mmHg) } \\
\begin{array}{l}\text { Pulmonary arterial oxygen } \\
\quad \text { saturation }\end{array}\end{array} \quad 68 \pm 3$ & $4 \pm 3$ \\
$\begin{array}{l}\text { Aortic oxygen saturation } \\
\text { Right-to-left shunt }\end{array}$ & $75 \pm 4 \%$ & $81 \pm 4 \%$ \\
$\begin{array}{l}\text { Left-to-right shunt } \\
\text { Indexed pulmonary vascular } \\
\left.\quad \text { resistance (mmHg/l/min per } \mathrm{m}^{2}\right)\end{array}$ & $2 \cdot 0 \pm 0 \cdot 3$ & $90 \pm 4 \%$ \\
\hline
\end{tabular}

$P<0.05$ for all comparisons between the two groups.

The data are given as the mean and standard error of the mean.

Indexed pulmonary vascular resistance $=$

Pulmonary arterial pressure-pulmonary arterial wedge pressure Indexed pulmonary blood flow

shunt, a small right-to-left shunt, and a moderate increase in pulmonary vascular resistance. When pulmonary stenosis was present the shunt was predominantly from right to left.

Good lateral ciné-left ventriculograms were available in 13 patients. Analysis of these showed whether contrast medium injected into the left ventricle flowed preferentially to the aorta or to the pulmonary artery. In nine patients the flow was mainly to the aorta, and seven of these had associated pulmonary stenosis. The flow went principally to the pulmonary artery in two patients, both of whom had obstructive lesions on the left side. Flow appeared to be divided equally between aorta and pulmonary artery in two patients. At necropsy the VSD was found to be subaortic in one of these.

Postero-anterior and lateral cineangiograms of sufficient quality to allow clear delineation of the relative positions of the great vessels were available in 16 patients. In one case the aorta and pulmonary artery lay side by side and were completely superimposed in the lateral view. This relationship was confirmed at surgery. In all the remaining patients the aorta was partially or completely in front of the anterior wall of the main pulmonary artery, at the level of the semilunar valves (Table 4). Two cases are illustrated in which the aorta is

Table 4 Relationship of great vessels on lateral cineangiogram

\begin{tabular}{|c|c|c|}
\hline $\begin{array}{l}\% \text { of aorta anterior to } \\
\text { main pulmonary artery }\end{array}$ & $\begin{array}{l}\text { Number of } \\
\text { pattents }\end{array}$ & $\begin{array}{l}\text { Number with } \\
\text { pulmonary stenosis }\end{array}$ \\
\hline \multirow[t]{2}{*}{$\begin{array}{r}100 \\
75 \\
50 \\
25 \\
0\end{array}$} & $\begin{array}{cc}6 & (38 \%) \\
3 & (19 \%) \\
5 & (31 \%) \\
1 & (6 \%) \\
1 & (6 \%)\end{array}$ & $\begin{array}{l}5 \\
2 \\
4 \\
0 \\
0\end{array}$ \\
\hline & $16(100 \%)$ & 11 \\
\hline
\end{tabular}

The relative positions were assessed at the level of the semilunar valves. 
entirely in front of the pulmonary artery (Figs 1 and 2).

\section{Management}

Corrective operations have been performed in 12 patients. One child aged 5 years required a Rastelli

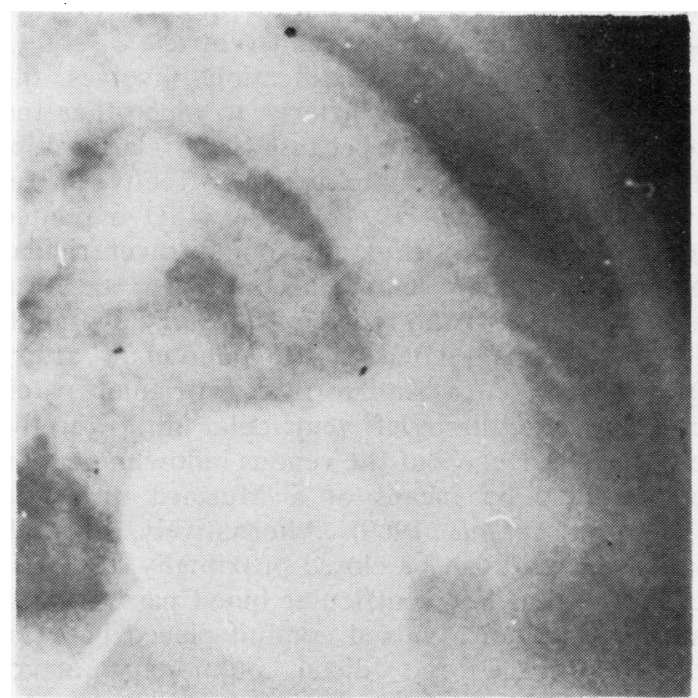

Fig. 1 Lateral view of left ventriculogram shows the aorta lying entirely in front of anterior wall of pulmonary artery at the level of the valves.

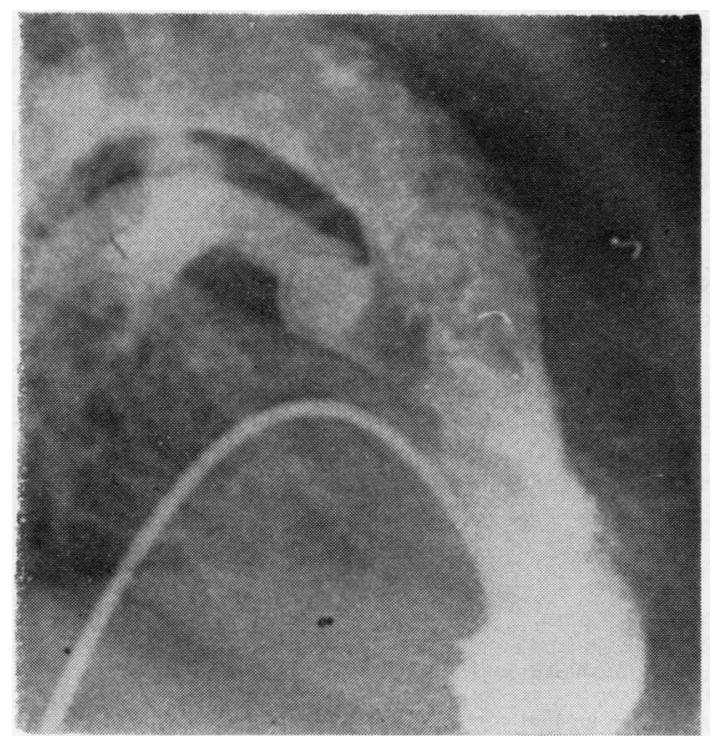

Fig. 2 Lateral view of right ventriculogram shows the aorta in front of pulmonary artery as in Fig. 1. procedure, in which closure of the VSD permitted flow from the left ventricle to the aorta and a valved conduit was inserted between the right ventricle and the pulmonary artery. In the remainder it was possible to close the VSD and redirect flow from the left ventricle to the aorta by means of an intraventricular patch. Three of the patients in the latter group died within 24 hours of surgery. Two returned to Europe in good health but have not written subsequently. The remaining seven have been followed for a mean of 6.5 years. Six are well, though one has a residual VSD with a $48 \%$ left-to-right shunt and a pulmonary to systemic resistance ratio of 0.06 . The seventh patient, who was 6 years old at the time of operation, had a resistance ratio before surgery of $0 \cdot 4$. Two months after operation she was shown to have a residual VSD with a net right-to-left shunt and a resistance ratio of $1 \cdot 2$.

Palliative operations were attempted in four patients. A Blalock shunt was performed in a 15year-old girl because a hypoplastic right ventricle prevented total correction. She is still well five years later. A Waterston shunt was initially successful in a 4-month-old girl but she died two years later. The two remaining patients died in the perioperative period. In one of these, a baby 5 days old, the anatomy made a shunt impossible.

The diagnosis of DORV was not made at cardiac catheterisation in three patients. The catheter data from another centre indicated tetralogy of Fallot in one case. This patient was one of those who died at the time of corrective operation. The other two (aged 3 weeks and 3 months) were demonstrated at catheterisation to have an associated coarctation and patent ductus arteriosus. In both cases the intracardiac defect was diagnosed as a VSD. Both babies died in the perioperative period. In one case the ductus was ligated, the coarctation resected, and the pulmonary artery banded. In the second case the ductus alone was ligated.

No operation has been performed in the remaining nine patients seen during life. Five are young and will come to operation. At present their arterial oxygen saturation is reasonable (mean $86 \%$ ) and their pulmonary vascular resistance is not raised (mean $1.8 \mathrm{mmHg} / 1 / \mathrm{min}$ per $\mathrm{m}^{2}$ ). Two have been lost to follow-up and two infants died after catheterisation but before operation.

Five infants were not examined by a cardiologist during life and the diagnosis of DORV was first made at necropsy. The oldest of these patients was 12 weeks old. The most remarkable feature in this group was the frequency of associated complex anomalies (Table 5). 
Table 5 Associated anomalies in five infants first diagnosed to have DORV at necropsy

\begin{tabular}{|c|c|c|}
\hline Sex & Age & Associated anomaly \\
\hline $\mathbf{M}$ & 5 days & Mitral atresia with hypoplastic left ventricle \\
\hline $\mathbf{M}$ & 9 days & $\begin{array}{l}\text { Situs inversus. Atrioventricular canal. } \\
\text { Total anomalous pulmonary venous drainage. } \\
\text { Hypoplasia of the main pulmonary artery }\end{array}$ \\
\hline $\mathbf{F}$ & 4 weeks & $\begin{array}{l}\text { Tubular hypoplasia of the aorta. PDA. } \\
\text { Hypoplasia of the lungs }\end{array}$ \\
\hline $\mathbf{F}$ & 6 weeks & Hypoplastic left ventricle. PDA \\
\hline $\mathbf{F}$ & 12 weeks & $\begin{array}{l}\text { Severe pulmonary valvar stenosis. Large } \\
\text { bronchial artery from ascending aorta to upper } \\
\text { lobe of left lung }\end{array}$ \\
\hline
\end{tabular}

\section{Discussion}

The anatomical definition of DORV is still controversial (Table 6). This confusion arises because DORV forms part of a spectrum of congenital cardiac anomalies (Gessner, 1966; Lev et al., 1972). Tetralogy of Fallot lies on one side and transposition on the other. The limits defined by the term DORV are therefore somewhat arbitrary. Some authors require, as we did, that both great arteries arise entirely from the right ventricle and that there should be mitral-aortic fibrous discontinuity. Others accept the definition that DORV exists when more than one and a half great vessels arise from the right ventricle, regardless of whether mitral-aortic discontinuity is present or not (Kirklin et al., 1973).

Consideration of the embryological development of the conotruncus (Goor and Edwards, 1973) makes it clear that both great arteries arise from the right ventricle through failure of the normal leftward shift of the conoventricular junction. This has also been demonstrated experimentally in the chick embryo (Gessner, 1966). Normally, mitralaortic fibrous continuity is established at a later stage by absorption of the subaortic conal myocardium. Unfortunately, mitral-aortic discontinuity, as a consequence of failure of absorption, is not a useful sign in the demarcation of DORV because absorption may not be complete in normal subjects (Rosenquist et al., 1976), and equally mitral-aortic continuity can occur when both great arteries arise from the right ventricle (Lev et al., 1972). A double muscular conus can also be present when the great arteries arise from separate ventricles (Angelini and Leachman, 1973). Consequently the only unambiguous criterion for the definition of DORV is that both great arteries should originate from the right ventricle.

A more relevant classification involves the relationship of the great arteries to each other and to the underlying VSD, because these relationships determine the appropriate type of corrective operation (Kinsley et al., 1974). If the VSD is related to the aorta (subaortic), then an intraventricular patch directing left ventricular outflow to the aorta is sufficient, as in the repair of tetralogy of Fallot. If the VSD is related to the pulmonary artery (subpulmonary), a similar intraventricular patch can be used to direct left ventricular outflow to the pulmonary artery, but the venous inflow must then be switched by means of a Mustard operation (Hightower et al., 1969). Alternatively, the pulmonary artery can be closed proximally, the VSD closed so that left ventricular blood passes to the aorta, and then a valved conduit placed between right ventricle and distal pulmonary artery (Rastelli procedure). Fortunately, intraventricular repair is usually possible. One report on 60 patients shows that the VSD is more likely to be subaortic $(67 \%)$ than subpulmonary $(22 \%)$, or remote from both great arteries $(8 \%)$, or related to both (3\%) (Sridaromont et al., 1976). In our series, only one patient had a Rastelli procedure while intraventricular correction was performed in 11 . The operative mortality of $25 \%$ is comparable with that of earlier reports: $22 \%$ (Gomes et al., 1971a) and $32 \%$ (Gomes et al., 1971b).

Analysis of the relationship of the VSD to the great arteries at cardiac catheterisation can be difficult. Oxygen saturation data may be helpful

Table 6 Definition of double outlet right ventricle

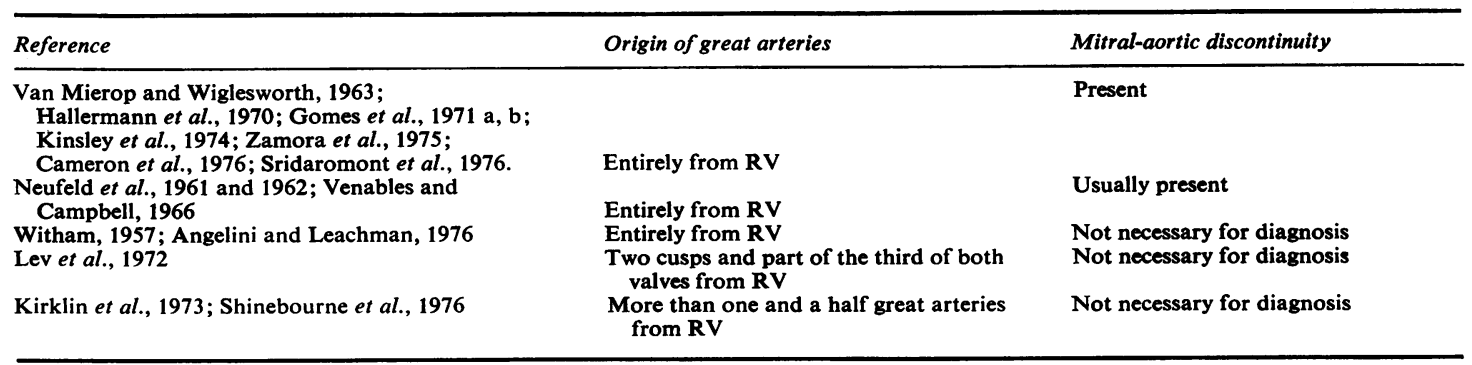

$\mathrm{RV}=$ right ventricle. 
if the samples are drawn simultaneously from the great arteries. In our data eight patients were found at operation or from angiography to have subaortic VSD. The oxygen saturation in the aorta was higher than that in the pulmonary artery in six of these patients and was the same in two. Similarly, in one recent report, 27 patients had systemic arterial saturations higher than pulmonary arterial saturations (Sridaromont et al., 1976). Twenty-four of these had subaortic ventricular septal defects. Thus when the aortic saturation is higher than the pulmonary arterial saturation the VSD is likely to be subaortic. Unfortunately, the reverse does not hold true, and when the pulmonary artery saturation is higher than the systemic saturation, the ventricular septal defect can be either subpulmonary or subaortic.

Left ventriculography is considered a more reliable method of determining the relationship of the VSD to the great arteries (Neufeld et al., 1962; Hallermann et al., 1970). In the absence of pulmonary stenosis, the flow of contrast medium to one or other great artery seems to be determined more by the relationship of the VSD to the valve of the arteries than by the relative vascular resistances (Neufeld et al., 1962). However, the severity of pulmonary stenosis, if present, inevitably influences the opacification of the pulmonary artery, even when the VSD is subpulmonary. A study correlating angiographic reports with operative or necropsy findings is necessary. In this series a diagnosis of subaortic VSD and pulmonary stenosis, made at catheterisation in three patients, was found to be correct at operation. In another patient without pulmonary stenosis the VSD was thought to be uncommitted on angiography but was shown to be subaortic at necropsy. In view of the difficulty of determining the commitment of the VSD from the catheter data, 'the surgeon must always verify the anatomical relations for himself at operation, since the pre-operative diagnosis may not be accurate in all details' (Kirklin et al., 1973).

Commitment of the VSD to one great artery has sometimes been noted to be associated with stenosis or hypoplasia of the other (Zamora et al., 1975). It is likely that in these instances failure of conoventricular alignment is associated with uneven septation of the conotruncus. Some form of right-sided obstruction was present in seven of our 10 patients in whom the VSD was clearly subaortic. Both patients with subpulmonary VSD were found to have hypoplasia of the left side, although one also had a $60 \mathrm{mmHg}$ gradient across the right ventricular outflow tract. Zamora et al. (1975), in their necropsy studies, found pulmonary stenosis to be confined entirely to hearts with a subaortic VSD. Despite this association the majority of those with subaortic VSD did not have pulmonary stenosis.

The incidence of pulmonary stenosis in DORV differs in pathological and clinical reports. Only six of the 33 patients $(18 \%)$ in one necropsy series had pulmonary stenosis (Zamora et al., 1975), and 14 out of $57(25 \%)$ in another (Angelini and Leachman, 1976). Eighteen of our 27 patients $(67 \%)$ seen during life had pulmonary stenosis. Another clinical study of 62 patients reports pulmonary stenosis in $47 \%$. It is likely that this difference arises through selection of patients. Teleologically, pulmonary stenosis may provide some advantage in the natural history of DORV. The patients with pulmonary stenosis also presented at a later age (6.2 years) than those without pulmonary stenosis ( $4 \cdot 3$ years). Patients with high pulmonary flows are known to be more susceptible to respiratory infections and to the development of pulmonary vascular disease. The pulmonary vascular resistance was significantly raised in our subjects without pulmonary stenosis in comparison with those with pulmonary stenosis. One developed an Eisenmenger syndrome. Pulmonary vascular obstructive disease was recorded in 21 of 33 patients in another study (Sridaromont et al., 1976).

There is a difference between the data reported in clinical and pathological studies regarding the relative positions of the great arteries. It is uncommon in clinical experience to find the aorta posterior to the pulmonary artery (Hallermann et al., 1970; Sridaromont et al., 1976), while this is the most common situation in the necropsy findings (Zamora et al., 1975; Angelini and Leachman, 1976; Cameron et al., 1976). Similarly, it is surprising that in none of the 33 specimens examined by Zamora et al. (1975) was the aorta entirely in front of the pulmonary artery, while these cases, as illustrated by Figs 1 and 2, formed the largest single group (38\%) in our data (Table 4). If the patients in whom the aorta is anterior to the pulmonary artery are more likely to have pulmonary stenosis, as suggested by Sridaromont et al. (1976), and if pulmonary stenosis has a protective effect, then the difference might have been explained. However, in the necropsy series of Angelini and Leachman (1976) pulmonary stenosis was present in 13 of 25 patients with normally related great arteries and in only one of those in whom the aorta was placed more anteriorly.

On the basis of the physical examination, electrocardiogram, and chest radiograph, DORV 
was suspected in only three of the 27 clinical patients in our series. The diagnosis of VSD was made in five of those without pulmonary stenosis. Tetralogy of Fallot was diagnosed in nine of those with pulmonary stenosis. The diagnosis in the remaining 10 patients usually reflected the associated defects.

The electrocardiogram can sometimes alert the cardiologist to the possibility of DORV. Mirowski et al. (1963) described the electrocardiographic findings in patients with DORV associated with pulmonary stenosis. First-degree heart block was present in $42 \%$, complete right bundle-branch block in $63 \%$, and left ventricular hypertrophy in $74 \%$ (all of whom had systemic-to-pulmonary shunts). While these abnormalities are seldom seen in tetralogy of Fallot, the corresponding figures in our cases with pulmonary stenosis were $24 \%, 0 \%$, and $6 \%$. Consequently these particular features are not helpful in the differential diagnosis. Marked left axis deviation (mean $-132^{\circ}$ ) was present in $47 \%$ of our patients with pulmonary stenosis. Left axis deviation is exceptionally rare in tetralogy of Fallot (Chesler et al., 1972) and thus its presence should raise the suspicion of DORV. The electrocardiogram did not help to differentiate DORV without pulmonary stenosis from VSD.

At cardiac catheterisation the diagnosis of DORV should be considered in all cases of VSD with right ventricular pressures at systemic level, and should be excluded in all cases of tetralogy. The danger of failing to make the diagnosis of DORV before surgery was borne out by the death of all three patients in this series in whom the condition was not recognised. Careful analysis of the ventriculogram (right or left) in the lateral view will prevent this error. Once DORV is seen in the perspective of a continuum of congenital cardiac anomalies, the anatomy, physiology, and several techniques of surgical correction are more easily understood. The significance of the difference between the clinical and necropsy studies, in terms of the relationship of the great vessels and the incidence of pulmonary stenosis, remains to be resolved.

We are grateful to Dr. J. E. Edwards and Professor E. Chesler for their critical review of the paper and to Miss Karen Leahy and Mrs. Pamela Peters for their help in the preparation of the manuscript. We thank the Medical Superintendent of Groote Schuur Hospital for permission to publish, and the Clyde Children's Heart Fund for financial support.

\section{References}

Angelini, P., and Leachman, R. D. (1973). Pulmonary artery originating anteriorly from the left ventricle. American Journal of Cardiology, 32, 840-845.

Angelini, P., and Leachman, R. D. (1976). The spectrum of double outlet right ventricle: an embryologic interpretation. Cardiovascular Diseases. Bulletin of the Texas Heart Institute, 3, 127-149.

Cameron, A. H., Acerete, F., Quero, M., and Castro, M. C. (1976). Double outlet right ventricle. Study of 27 cases. British Heart Journal, 38, 1124-1132.

Chesler, E., Beck, W., and Schrire, V. (1972). Left anterior hemiblock and right bundle branch block before and after surgical repair of tetralogy of Fallot. American Heart Journal, 84, 45-52.

Gessner, I. H. (1966). Spectrum of congenital cardiac anomalies produced in chick embryos by mechanical interference with cardiogenesis. Circulation Research, 18, 625-633.

Gomes, M. M. R., Weidman, W. H., McGoon, D. C., and Danielson, G. K. (1971a). Double-outlet right ventricle without pulmonic stenosis. Circulation, 43 and 44, Supplement 1, 31-36.

Gomes, M. M. R., Weidman, W. H., McGoon, D. C., and Danielson, G. K. (1971b). Double-outlet right ventricle with pulmonic stenosis. Circulation, 43, 889-894.

Goor, D. A., and Edwards, J. E. (1973). The spectrum of transposition of the great arteries. With specific reference to the developmental anatomy of the conus. Circulation, 48, 406-415.

Hallermann, F. J., Kincaid, O. W., Ritter, D. G., Ongley, P. A., and Titus, J. L. (1970). Angiocardiographic and anatomic findings in the origin of both great arteries from the right ventricle. American Journal of Roentgenology, Radium Therapy and Nuclear Medicine, 109, 51-66.

Hightower, B. M., Barcia, A., Barceron, L. M., and Kirklin, J. W. (1969). Double-outlet right ventricle with transposed great arteries and subpulmonary ventricular septal defect. Circulation, 39 and 40, Supplement 1, 207-213.

Kinsley, R. H., Ritter, D. G., and McGoon, D. C. (1974). The surgical repair of positional anomalies of the conotruncus. Journal of Thoracic and Cardiovascular Surgery, 67, 395-403.

Kirklin, J. W., Pacifico, A. D., Bargeron, L. M., and Soto, B. (1973). Cardiac repair in anatomically corrected malposition of the great arteries. Circulation, 48, 153-159.

Lev, M., Bharati, S., Meng, L., Liberthson, R. R., Paul, M. H., and Idriss, F. (1972). A concept of double-outlet right ventricle. Journal of Thoracic and Cardiovascular Surgery, 64, 271-281.

Mirowski, M., Mehrizi, A., and Taussig, H. B. (1963). The electrocardiogram in patients with both great vessels arising from the right ventricle combined with pulmonary stenosis. Circulation, 28, 1116-1127.

Neufeld, H. N., Dushane, J. W., Wood, E. H., Kirklin, J. W., and Edwards, J. E. (1961). Origin of 
both great vessels from the right ventricle. 1 . Without pulmonary stenosis. Circulation, 23, 399-412.

Neufeld, H. N., Lucas, R. V., Lester, R. G., Adams, P., Anderson, R. C., and Edwards, J. E. (1962). Origin of both great vessels from the right ventricle without pulmonary stenosis. British Heart Journal, 24, 393-408.

Rosenquist, G. G., Clark, E. B., Sweeney, L. J., and McAllister, H. A. (1976). The normal spectrum of mitral and aortic valve discontinuity. Circulation, 54, 298-301.

Shinebourne, E. A., Macartney, J., and Anderson, R. H. (1976). Sequential chamber localizationlogical approach to diagnosis in congenital heart disease. British Heart Journal, 38, 327-340.

Sridaromont, S., Feldt, R. H., Ritter, D. G., Davis, G. D., and Edwards, J. E. (1976). Double outlet right ventricle: hemodynamic and anatomic correlations. American Journal of Cardiology, 38, 8594.

Van Mierop, L. H. S., and Wiglesworth, F. W. (1963). Pathogenesis of transposition complexes. 2. Anoma- lies due to faulty transfer of the posterior great artery. American Journal of Cardiology, 12, 226232.

Van Praagh, R. (1973). Do side by side great arteries merit a special name? American Journal of Cardiology, 32, 874-876.

Venables, A. W., and Campbell, P. E. (1966). Double outlet right ventricle. A review of 16 cases with 10 necropsy specimens. British Heart Journal, 28, 461471.

Witham, A. C. (1957). Double outlet right ventricle. A partial transposition complex. American Heart Journal, 53, 928-939.

Zamora, R., Moller, J. H., and Edwards, J. E. (1975). Double-outlet right ventricle. Anatomic types and associated anomalies. Chest, 68, 672-677.

Requests for reprints to: Dr. H. S. Joffe, Cardiology Unit, Red Cross War Memorial Children's Hospital, Klipfontein Road, Rondebosch, Cape Town 7700, South Africa. 